\title{
Two types of refuge have opposite effects on the size of larval aggregations in a tropical defoliator
}

\author{
FinBARR G. HORGAN* \\ Escuela de Biología, Universidad de El Salvador, Final 25 Avenida Norte, San Salvador, El Salvador
}

Key words. Defence, density responses, El Salvador, Ficus, gregariousness, parasitism, refuges, Tachinidae, tiger moth, tropical defoliator

\begin{abstract}
Many gregarious insects aggregate in naturally occurring refuges on their host plants. However, when refuges are filled, they may be forced to aggregate on exposed areas of the plant. This study examines the effects of refuge saturation on group size and defence against parasitism in larvae of Ammalo helops Cramer (Lepidoptera: Arctiidae) that form day-resting groups on the trunks of weeping laurel, Ficus benjamina L., in El Salvador. Population densities, group sizes and parasitism were recorded on eight trees for each of four generations in 1995 and 1996. When population densities were low, all larvae were located in small groups in naturally occurring structural refuges (rotted out holes, spaces between crossing branches and under aerial roots) on the host plant. In contrast, when population densities were high and structural refuges were full, many larvae formed significantly larger groups (density refuges) on the open trunk. Between 20 and $24 \%$ of late-instar larvae were parasitized and this was inversely dependent on the size of within tree populations, in spite of populations being fragmented among structural refuges. Similarly, in a study carried out at a different location on young trees without structural refuges, parasitism of larvae was inversely related to group size. Although parasitism rates decreased with increasing group size, most larvae preferentially selected the small naturally occurring refuges, where groups were restricted to low densities. If this behaviour is an adaptive trait, I speculate that parasitism (or some other unmeasured mortality factor) is lower in naturally occurring refuges than in large open groups.
\end{abstract}

\section{INTRODUCTION}

Most Lepidoptera lay their eggs in groups. However, only a relatively small number of species maintain gregariousness after eclosion (Stamp, 1980; Hunter, 2000). Evidence suggests that gregariousness following egg hatch is maintained when it increases individual fitness by acting as a defence against predators and parasitoids (defence hypothesis) (Stamp, 1981; Iwakuma \& Morimoto, 1984; Hunter, 2000) where the per capita risk of attack decreases as group size increases (i.e. "hiding in a group", Turchin \& Kareiva, 1989). However, the size of larval groups is influenced by numerous environmental and physiological conditions, such as food availability, host plant species, predation risk, climatic factors as well as larval age and experience (Stamp, 1984; Cornell et al., 1987; Beingolea \& Vásquez, 1996; Klok \& Chown, 1999).

Plant architecture plays an important role in insect defence, even in solitary species (Wang et al., 1997, 1999; Neuvonen, 1999), as it can provide spatial refuges from natural enemies. However, naturally occurring refuges, such as rotted-out holes, are likely to be small and may not allow large numbers of larvae to occupy them. Thus, gregarious herbivorous insects may have to choose between occupying refuges provided by the host plant and forming large groups in exposed areas. To my knowledge the importance of refuge seeking for gregarious larvae has not been examined in any previous study. By understanding how gregarious larvae respond to plant architecture under fluctuating population densities, we may gain further insight into the defence strategies of gregarious species and the mechanisms behind their longterm population trends.

The present study examines gregariousness in late instars of the Neotropical moth Ammalo helops Cramer (Lepidoptera: Arctiidae) that feed on the foliage of introduced weeping laurel (Ficus benjamina L.) in El Salvador. Weeping laurel, especially larger specimens, are often architecturally complex. Mature laurels are generally buttressed with complicated aerial root systems (Fails et al., 1982). Populations of $A$. helops were monitored at one site in 1995 and 1996 and at a second site in 1999, noting the sizes, positions, and numbers of groups. Here, the effects of population density on the location of groups within trees, group size and parasitism are examined, and the potential benefits of gregariousness and refuge seeking as a defence against parasitism are discussed.

\section{MATERIAL AND METHODS}

\section{Study species}

Ammalo helops is a large arctiid moth that occurs throughout the Neotropics. The species feeds on Ficus spp. (Beingolea \& Vásquez, 1994; D. Janzen, pers. commun.). Eggs are laid in groups on the trunk or on leaves. Potential fecundity for the species is approximately $246 \pm 23$ eggs (mean \pm SE, $n=16$ ) (personal observation). There are eight instars and gregariousness is apparent throughout larval development. Young larvae (L1-L4) feed cooperatively and remain high in the tree canopy (Beingolea \& Vásquez, 1994). This behaviour changes at L5: during the day, L5-L8 instars form resting-groups on the trunk or

\footnotetext{
* Present address: Teagasc, Oak Park Research Centre, Carlow, Co. Carlow, Ireland; e-mail: fhorgan@oakpark.teagasc.ie
} 
lowest branches of the host plant. At dusk the larvae migrate to the tree canopy where they feed solitarily. Pupae are also strongly gregarious. Prepupae migrate to the tree canopy where they form pupal masses (Beingolea \& Vásquez, 1994). In San Salvador there are two generations each year. Eggs are laid in June and July during the rainy season and larval development is completed in about four months. A second generation of adults emerges to lay eggs in November and December. Much of the second-generation larval development (about six to seven months) occurs during the dry season.

\section{Study sites}

Studies were conduced at the San Salvador campus of the University of El Salvador in 1995 and 1996. The campus is located in downtown San Salvador and at the time of study had a large area of parkland with many overgrown areas of high grasses and numerous scattered ornamental trees. Ornamental weeping laurel (Ficus benjamina L.) were common throughout the campus. A group of eight weeping laurel were located in a small grove and adjacent car-lot within an area of 0.5 ha. All laurels were mature trees, approximately $20 \mathrm{~m}$ high and with a basal circumference of approximately $2.5 \mathrm{~m}$. In 1999, groups were studied on 11 trees located on a green strip along the San Salvador-Sonsonate highway at San Andrés, immediately outside San Salvador. These trees reached a height of approximately $6 \mathrm{~m}$ and had a basal circumference of approximately 0.4 $\mathrm{m}$.

\section{Larval aggregations and parasitism}

Four generations of $A$. helops were monitored between July 1995 and September 1996. Groups of late instars (L5-L8) were located on the trees and the larvae were counted on a number of occasions each June/July, corresponding to the first generation where eggs had been laid the previous December (dry season), and September/October, corresponding to the second generation where eggs had been laid in June and July (wet-season). The within-tree location and size of each group was recorded at each count and the number of solitary individuals also noted. The mean sizes of groups in refuges and on exposed areas of the trunk were compared using a t-test on log-transformed data from the wet season generation in 1995 when populations were highest. Regression was used to evaluate the relationship between population density and the proportional occurrence of individuals in groups. Residuals were plotted following analyses to ensure homogeneity and normality.

During each generation, three or four samples of between ten and 50 larvae from each tree were taken at two-week intervals and reared individually in an insectary on cut foliage to estimate the incidence of parasitism. Where fewer than ten individuals occurred on a tree, all prepupae were collected. Because of high mortality during rearing in 1995, data on the per-tree levels of parasitism were available only for the second generation of 1996. Parasitoids were not identified to species level. Voucher specimens were deposited at the Escuela de Biología insect collection, Universidad de El Salvador and the Canadian National Collection (Tachinidae) (Ottawa, Canada).

Since larvae change positions within and between groups on individual trees, the within-tree population cannot be divided on the basis of whether they selected a naturally occurring refuge (or not) nor on the size of the larval group. For this reason further samples were taken in 1999 from groups of resting larvae on young laurels at San Andrés. These larvae formed a single large group on each tree. This allowed determination of the effect of group size alone (as opposed to per-tree population for the University of El Salvador site where individuals may have moved between structural and density refuges) on the incidence of parasitism in $A$. helops, for which no such previous data exists. Twenty larvae (L7-L8), randomly collected on a single occasion from day-resting groups were dissected in order to determine the incidence of parasitism. The relationship between levels of parasitism and within-tree population size, or group size, was determined using linear regression. All density data were $\log (\mathrm{x} \pm 0.1)$-transformed. Residuals were plotted following analyses to check for homogeneity and normality.

\section{RESULTS}

\section{Larval aggregations}

Late instars (L5-L8) of $A$. helops migrated to the bases of the trees or the main trunk in groups that settled at heights ranging from ground level to $7 \mathrm{~m}$ from the ground $(2.69 \pm 0.25 \mathrm{~m}$; mean $\pm \mathrm{SE})$. There was no relationship between group size and the height at which groups

TABLE 1. Size, location, and tent formation for groups of $A$. helops on weeping laurel $(F$. benjamina) indicating the conditions that constitute "structural" and "density" refuges.

\begin{tabular}{|c|c|c|}
\hline Group size & Location & Tent \\
\hline \multicolumn{3}{|c|}{ Density refuge groups } \\
\hline$>1000^{1}$ & Smooth surface of trunk & No \\
\hline 100 to 500 & $\begin{array}{l}\text { Smooth surface of trunk } \\
\text { Between first bifurcation } \\
\text { Between crossing of large branches } \\
\text { Inside buttress }\end{array}$ & $\begin{array}{l}\text { No } \\
\text { No } \\
\text { No } \\
\text { No }\end{array}$ \\
\hline \multicolumn{3}{|c|}{ Structural refuge groups } \\
\hline 100 to 200 & Inside buttress & Yes \\
\hline 5 to 100 & $\begin{array}{l}\text { Between closely crossing branches } \\
\text { In trunk indentations } \\
\text { Under roots that cross branches }{ }^{2} \\
\text { In rotted-out holes }\end{array}$ & $\begin{array}{l}\text { No } \\
\text { Yes } \\
\text { Yes } \\
\text { Yes }\end{array}$ \\
\hline \multicolumn{3}{|c|}{ Solitary individuals } \\
\hline$<5$ & All of the above & No \\
\hline
\end{tabular}

${ }^{1}$ outside the main group of trees in the study;

${ }^{2}$ crossing branches/roots are regarded as refuges where the branches touched or were so close that the larvae could only be removed one-by-one from the side during sampling. 
(a)

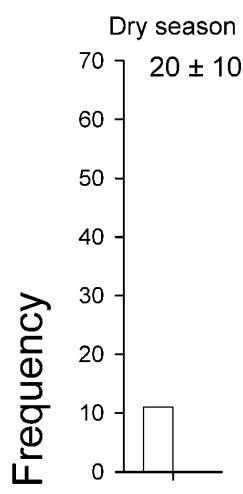

(c)

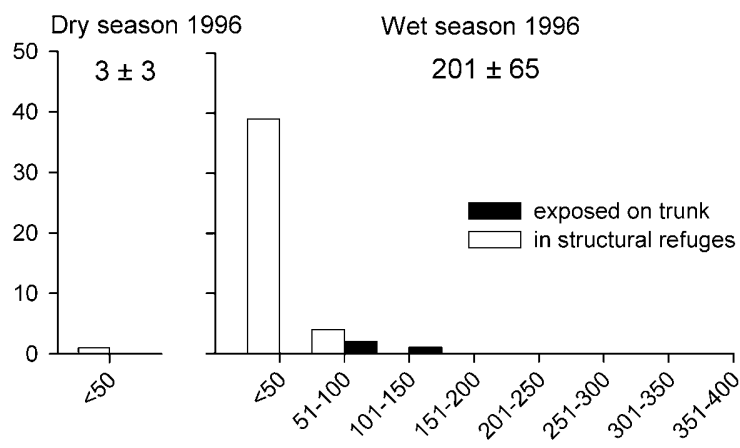

Group size

Fig. 1. Frequency of aggregations with different numbers of late-instar $A$. helops on exposed areas of the trunk and in naturally occurring structural refuges on weeping laurel at the University of El Salvador during four consecutive generations: (a) dry season of 1995, (b) wet season of 1995, (c) dry season of 1996 and (d) wet season of 1996. Numbers are mean population size per tree \pm standard error.

formed on the host trunk (linear regression: $\mathrm{R}^{2}=0.01$, $\left.\mathrm{F}_{1,79}=0.21, \mathrm{P}=0.650\right)$. Groups varied slightly in size on successive days. However, in general, resting groups were formed at the same locations each day and even in different years. Groups varied from three to 450 larvae (44 \pm 4.09 ; mean $\pm \mathrm{SE}$ ) among the eight laurels. A single group of over 1200 larvae was observed in 1995 on a laurel outside the study area at the University.

Larval aggregations were divided into two types (Table 1). Small groups of larvae occupied small depressions in trunk indentations, rotted out holes, certain parts of the buttress and between crossing and joining branches or aerial roots. Groups that occurred in such naturally occurring refuges were generally small and depended largely on the size of the refuge. Slightly larger groups of larvae formed in certain large trunk indentations and relatively open parts of the buttress. In almost all cases, larvae in these natural refuges constructed simple tents that contained frass and exuviae. In contrast, the largest groups were generally located on the smooth surface of the trunk and frequently occurred between the principal main branches at the first trunk bifurcation. Such groups were never covered by a tent and groups were not necessarily

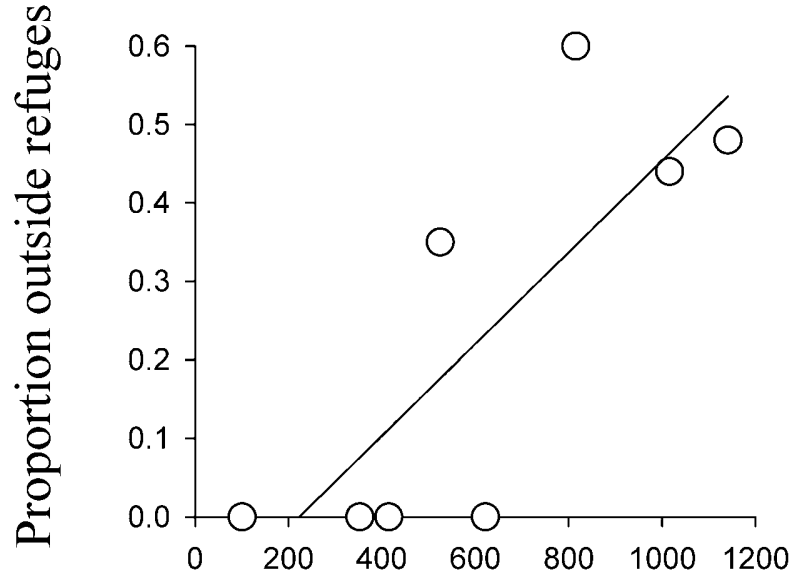

Density (Larvae per tree)

Fig. 2. Relationship between the proportion of late-instar $A$. helops on weeping laurel at the University of El Salvador outside natural refuges and population size on individual trees in $1995(\mathrm{n}=8)$.

kin-related because many group sizes exceeded the maximum-recorded potential fecundity of 400 (Horgan, unpubl.). Very small groups (less than five individuals) and solitary individuals showed no obvious location trends and may include caterpillars that were 'lost' from larger groups (Table 1). Groups located in naturally occurring refuges were significantly smaller $(37 \pm 5$; mean $\pm \mathrm{SE})$ than those on open areas on the trunk $(135 \pm$ 23; mean \pm SE) (Fig. 1) ( $\mathrm{t}$-test: $\mathrm{t}=-9.25$, df $=88, \mathrm{P}<$ $0.001)$.

The population fluctuated between a low density first (dry season) generation and a high density second (wet season) generation (Fig. 1). All larvae occupied naturally occurring refuges during the dry season, when densities were lowest (Fig. 1a, c). Three large exposed groups were observed during the wet season in 1996 (Fig. 1d), when densities were moderate, but many large exposed groups occurred during the wet season in 1995 (Fig. 1b), when populations were highest. The occurrence of large numbers of caterpillars on exposed areas of the trunk was directly related to within-tree population density (Fig. 2) (linear regression, $\mathrm{y}=-0.13+0.001 \mathrm{x}, \mathrm{R}^{2}=0.62, \mathrm{~F}_{1,7}=$ 9.98, $\mathrm{P}=0.019)$.

\section{Influence of larval density on parasitism - no structural refuges available}

Dissections of larvae from San Andrés indicated parasitism by microhymenopterans $(3 \%)$ (possibly microgastrinids) and flies (6\%) (possibly tachinids). An inverse density dependent relationship between parasitism and group size was observed on young laurel, which due to its smooth bark does not provide any natural refuges (Fig. 3) (linear regression: $\log \mathrm{y}=-0.003(\log \mathrm{x})-0.317, \mathrm{R}^{2}=$ $0.37, \mathrm{~F}_{1,10}=5.20, \mathrm{P}=0.049$ ). 


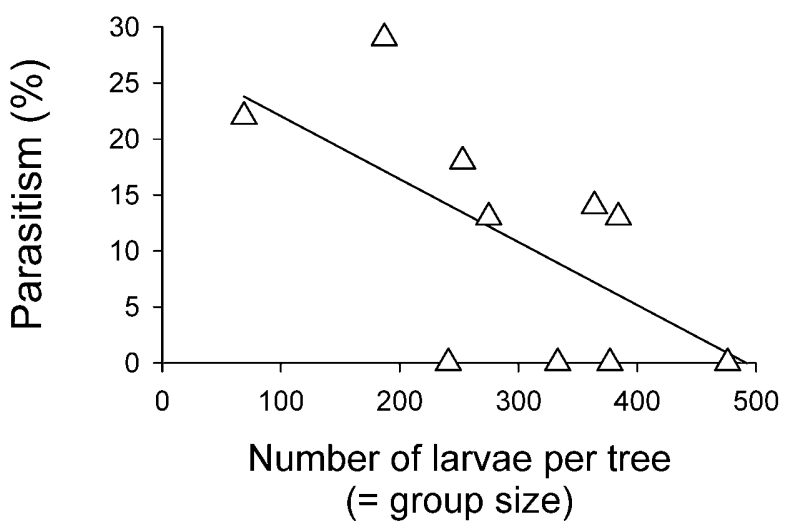

Fig 3. Relationship between percent parasitism of late-instar larvae of A. helops and the larval group size on young laurel at San Andrés in 1999. Note that group size on these young laurel trees was equal to the number of larvae per tree, since no structural refuges were available. Data are back transformed $(\mathrm{n}=$ $11)$.

\section{Influence of larval density on parasitism - structural refuges available}

No larvae in the low density, dry season generations were parasitized at the University of El Salvador. Although no L5 larvae were parasitized during the wet seasons, three tachinids [Winthemia sp., Leschenaultia sp., and a further unidentified species (Diptera: Tachinidae)] ( $4 \%$ in $1995,16 \%$ in 1996), a microgastrinid wasp, Conura sp. (Hymenoptera: Microgastrinidae) (17\% in $1995,7.5 \%$ in 1996), and an unidentified sarcophagid fly (Diptera: Sarcophagidae) (0 in 1995, 0.5\% in 1996) parasitized L6-L8 larvae. Mean total parasitism in the wet season ranged from $20 \%$ (1995) to $24 \%$ (1996). Mortality caused by parasitism in 1996 was inversely related to larval density on six trees where all larvae occurred in natural refuges (Fig. 4) (linear regression: $\log \mathrm{y}=$ $\left.-513(\log \mathrm{x})-2.614, \mathrm{R}^{2}=0.74, \mathrm{~F}_{1,5}=9.38, \mathrm{P}=0.028\right)$.

\section{DISCUSSION}

A number of studies have documented the selection of naturally occurring refuges (Carrier, 1992; Brouat et al., 2001; Davies et al., 2001; Mehltreter et al., 2003) or the formation of large aggregations by insects and mites (Stamp, 1981; Iwakuma \& Morimoto, 1984; Turchin \& Karieva, 1989; Aukema \& Raffa, 2004), both of which reduce mortality due to natural enemies. However, the present study may be the first to document a case where insects on the same host plant are found in both types of refuges, hereafter referred to as "structural" and "density" refuge. During generations when population densities of $A$. helops on weeping laurel were low, all larvae were located in small groups in naturally occurring refuges (rotted out holes, spaces between crossing branches and under aerial roots), which they often covered with coarse tents. In contrast, when population densities were high, and most naturally occurring refuges were full, many larvae formed significantly larger groups on the open trunk. Groups on open parts of the trunk did not form

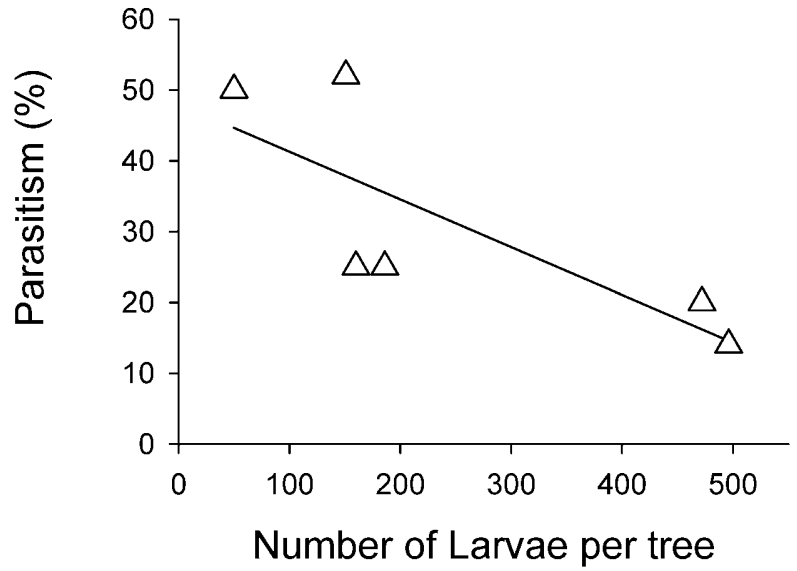

Fig 4. Relationship between percent parasitism of late-instar larvae of $A$. helops and the within-tree population size on mature laurel at the University of El Salvador in 1996 when all larvae were aggregated in naturally occurring refuges. Data are back transformed $(n=6)$.

tents presumably because in such locations the larvae lacked a three-dimensional frame on which to hang the tent. These observations indicate that larvae occupied naturally occurring refuges first and only formed large exposed groups after all natural refuges were occupied.

Mortality of $A$. helops larvae due to parasitoids can be high. Between 20 and $24 \%$ of larvae were parasitized at the University of El Salvador during the wet season (this study), and between 33 and $96 \%$ of $A$. helops larvae were parasitized on weeping laurel in a similar urban habitat in Lima, Peru, (Beingolea \& Vásquez, 1996). Levels of parasitism and grouping behaviour of $A$. helops larvae in natural, forested habitats have not been recorded; however, it is likely that similar grouping behaviour occurs in natural habitats on structurally complex host trees and that this will have a similar effect on predation risk. In the present study, gregariousness reduced the risk of parasitism for $A$. helops larvae. Whether in smaller groups in naturally occurring refuges or in large exposed groups on tree trunks, percent parasitism of larvae was inversely related to group size. A number of studies indicate that mortality of gregarious larvae outside of structural refuges increases when groups are experimentally fragmented (Stamp, 1981; Iwakuma \& Morimoto, 1984; Stamp \& Bowers, 1988), a result consistent with studies carried out with fish and marine invertebrates (Tyler, 1995; Herrnkind et al., 2001), birds (Elliot, 1985; Cresswell, 1994) and mammals (Hill \& Dunbar, 1998; Hebblewhile \& Pletscher, 2002; Ebensperger \& Wallem, 2003). However, in this study within-tree populations of $A$. helops were often naturally fragmented because they used small structural refuges with limited space for larvae.

Lower rates of parasitism among late-instar larvae of $A$. helops in larger groups may result from increased efficiency of defence when in groups or to a dilution effect, where the number of potential attacks is small compared to the size of the group, as postulated for schools of fish 
(i.e. Tyler, 1995). During the day, unidentified tachinids could be observed perched on the trunks close to larval groups. These parasitoids made short dashes towards larvae on the outer perimeter of the groups, presumably to oviposit. During attacks, larvae at the group edge exhibited short bursts of vigorous head-flicking while larvae at more central locations were undisturbed (personal observation). As over $50 \%$ of all parasitism in the study was attributable to tachinids, this observation suggests that late instars located at the group perimeter are most susceptible to parasitoids. Thus, in this system, reduced rates of parasitism in larger (versus smaller) exposed aggregations may be due to both an increased efficiency of group versus individual defence [e.g., head-flicking is quite effective for groups of sawflies versus for individuals (Codella \& Raffa, 1995)] and to an indirect effect of dilution associated with the position occupied in large groups. In larger aggregations a smaller proportion of larvae will be located on the group perimeter, where parasitism risk may be highest.

An inverse relationship between aggregation size and the incidence of parasitism among late-instar larvae of $A$. helops in naturally occurring structural refuges is more difficult to explain. Larvae may aggregate in natural refuges because of favourable microclimates that improve larval thermoregulation and reduce water loss (see also Klok \& Chown, 1999). Aggregation to structural refuges may also enhance defence; due to the three dimensional nature of many structural refuges, the proportion of larvae on the outer perimeter should be lower for a given aggregation size than that for exposed aggregations, and the access to larvae on the perimeter of aggregations should be more limited due to the tent spun above them, which they coat with irritating hairs, exuviae and frass. Nevertheless, as for exposed aggregations, the proportion of larvae on the perimeter of the aggregation likely decreases with increasing aggregation size, which may maintain an inverse density dependent relationship between group size and parasitism even when all the larvae are located in structural refuges.

If refuge selection by $A$. helops is an adaptive trait, then the fitness of larvae occupying structural refuges where aggregation size is very limited, should be higher than that of larvae forming large exposed groups, which should be higher than that of larvae seeking no refuge (i.e., solitary larvae). The present study demonstrates that parasitism rates are lower in larger than smaller aggregations, regardless of whether larvae are in structural refuges or exposed aggregations, and that larvae form larger (exposed) aggregations when aggregation size is not limited by the size of the (structural) refuge. However, because larvae may move between structural and density refuges in the same tree, it was not possible to compare the levels of parasitism resulting from either strategy. Due to rearing difficulties, I was not able to measure percent parasitism or survival for larvae during the wet season in 1995, the only generation when a large proportion of larvae formed large exposed aggregations on some but not all trees, or for larvae on mature versus immature laurel trees, which provided and did not provide structural refuges during the same generation. Thus future studies are needed to determine if the formation of small aggregations in naturally occurring structural refuges results in higher fitness that the formation of exposed aggregations. Nevertheless, this study clearly shows that gregariousness is an adaptive trait for $A$. helops larvae but that they prefer the refuge provided by complex plant architecture to that provided by group living.

ACKNOWLEDGEMENTS. I thank S. Diaz Sierra, Y. López Ventura and V. Valencia Durán for help in data collection, and R. Johns, C. Macquarrie, G. Moreau, D. Quiring and anonymous reviewers for helpful comments that improved the manuscript. Permission to collect specimens was granted through the Natural Resources Institute of the Ministry of Agriculture and Livestock (El Salvador).

\section{REFERENCES}

Aukema B.H. \& Raffa K.F. 2004: Does aggregation benefit bark beetles by diluting predation? Links between a groupcolonisation strategy and the absence of emergent multiple predator effects. Ecol. Entomol. 29: 129-138.

Beingolea O.D. \& VÁsquez G. 1994: Notas bioecológicas sobre el "gusano peludo del ficus" en Lima. Rev. Per. Entomol. 36: $39-44$.

Beingolea O.D. \& VÁsquez G. 1996: Dinámica de poblaciones de Ammalo helops var. trujillaria Dognin (Lepidoptera: Arctiidae). Rev. Per. Entomol. 38: 29-33.

Brouat C., Garcia N., Andary C. \& McKey D. 2001: Plant lock and ant key: pairwise coevolution of an exclusion filter in an ant-plant mutualism. Proc. R. Soc. Lond. (B) 268: 2131-2141.

CARRIER Y. 1992: larval dispersal from potential hosts within a population of a generalist herbivore, Choristoneura rosaceana. Entomol. Exp. Appl. 65: 11-19.

Codella S.G. \& Raffa K.F. 1995: Contributions of female oviposition patterns and larval behavior to group defense in conifer sawflies (Hymenoptera, Diprionidae). Oecologia 103: 24-33.

Cornell J.C., Stamp N.E. \& Bowers M.D. 1987: Developmental change in aggregation, defense and escape behavior of buckmoth caterpillars, Hemileuca lucina (Saturniidae). Behav. Ecol. Sociobiol. 20: 383-388.

Cresswell W. 1994: Flocking is an effective anti-predation strategy in redshanks, Tringa tetanus. Anim. Behav. 47: 433-442.

Davies J.T., Allen G.R. \& Williams M.A. 2001: Intraplant distribution of Acalitus essigi (Acari: Eriophyoidea) on blackberries (Rubus fruticosus agg.). Exp. Appl. Acarol. 25: 625-639.

EbensPerger L.A. \& Wallem P.K. 2002: Grouping increases the ability of the social rodent, Octodon degus, to detect predators when using exposed microhabitats. Oikos 98: 491-497.

ELLIOT R.D. 1985: The effects of predation risk and group-size on the anti-predator responses of nesting lapwings Vanellus vanellus. Behaviour 92: 168-187.

Fails B.S., LewIS A.J. \& BARDEN J.A. 1982: Anatomy and morphology of sun and shade-grown Ficus benjamina. J. Am. Soc. Hortic. Sci. 105: 724-757.

Hebblewhite M. \& Pletscher D. 2002: Effects of elk group size on predation by wolves. Can. J. Zool. 80: 800-809.

HeINRICH B. 1979: Foraging strategies of caterpillars: leaf damage and possible predator avoidance strategies. Oecologia 42: 325-337. 
Herrnkind W.F., Childress M.J. \& Lavalli K.L. 2001: Cooperative defence and other benefits among exposed spiny lobsters: inferences from group size and behaviour. Mar. Freshwater Res. 52: 1113-1124.

Hill R.A. \& Dunbar R.I.M. 1998: An evaluation of the roles of predation rate and predation risk as selective pressures on primate grouping behaviour. Behaviour 135: 411-430.

HUNTER A.F. 2000: Gregariousness and repellent defences in the survival of phytophagous insects. Oikos 91: 213-224.

IwAKuma T. \& MоRiмото N. 1984: An analysis of larval mortality and development in relation to group size in Dictyoploca japonica (Lepidoptera: Saturniidae), with special reference to field populations. Res. Popul. Ecol. 26: 51-73.

Klok C.J. \& Chown S.L. 1999: Assessing the benefits of aggregation: thermal biology and water relations of anomalous Emperor Moth caterpillars. Funct. Ecol. 13: 417-427.

Mehltreter K., Rojas P. \& Palacios-Rios M. 2003: Moth larvae-damaged giant leather-fern Acrostichum danaeifolium as host for secondary colonization by ants. Am. Fern. J. 93: $49-55$.

Neuvonen S. 1999: Random foraging by herbivores: complex patterns may be due to plant architecture. J. Ecol. 87: $526-528$.

Stamp N.E. 1980: Egg deposition patterns of butterflies: why do some species cluster their eggs rather than deposit them singly? Am. Nat. 115: 367-380.
Stamp N.E. 1981: Effect of group size on parasitism in a natural population of the Baltimore checkerspot Euphydryus phaeton. Oecologia 49: 201-206.

StAmP N.E. 1984: Foraging behavior of tawny emperor caterpillars (Nymphalidae: Asterocampa clyton). J. Lepid. Soc. 38: 186-191.

Stamp N.E. \& Bowers M.D. 1988: Direct and indirect effects of predatory wasps (Polistes spp.: Vespidae) on gregarious caterpillars (Hemileuca lucina: Saturniidae). Oecologia 75: 619-624.

Turchin P. \& Kareiva P. 1989: Aggregation in Aphis varians: an effective strategy for reducing predation risk. Ecology 70: 1008-1016.

TYLER W.A. 1995: The adaptive significance of colonial nesting in a coral-reef fish. Anim. Behav. 49: 949-966.

Wang B., Ferro D.N. \& Hosmer D.W. 1997: Importance of plant size, distribution of egg masses, and weather conditions on egg parasitism in the European corn borer, Ostrinia nubilalis by Trichogramma ostriniae in sweet corn. Entomol. Exp. Appl. 83: 337-345.

Wang B., Ferro D.N. \& Hosmer D.W. 1999: Effectiveness of Trichogramma ostriniae and T. nubilale for controlling the European corn borer Ostrinia nubilalis in sweet corn. Entomol. Exp. Appl. 91: 297-303.

Received September 22, 2004; revised and accepted February 28, 2005 